\title{
Runoff of the Tire-Wear Compound, Hexamethoxymethyl-Melamine into Urban Watersheds
}

\author{
Cassandra Johannessen ${ }^{1}\left[\right.$ (D) Paul Helm² ${ }^{2}$ Chris D. Metcalfe ${ }^{1}$
}

Received: 3 September 2020 / Accepted: 8 January 2021 / Published online: 30 January 2021

(c) The Author(s), under exclusive licence to Springer Science+Business Media, LLC part of Springer Nature 2021

\begin{abstract}
Hexamethoxymethyl-melamine (HMMM) is used as a crosslinking agent in resins and plastics and in the manufacture of tires. In the present study, surface water samples were collected from two rivers adjacent to high traffic highways in the Greater Toronto Area in Ontario, Canada. Composite samples collected from the Don River and Highland Creek during rain events and a period of rapid snowmelt were preconcentrated using solid phase extraction and analyzed using liquid chromatography with high-resolution mass spectrometry. Elevated concentrations ( $>1 \mu \mathrm{g} / \mathrm{L})$ of HMMM were detected in surface waters during rain events in October of 2019 and during snow melt in early March of 2020. There were lower average concentrations of HMMM detected during rain events in the winter and spring of 2020. Temporal profiles of changes in the concentrations of HMMM in composite samples collected every $3 \mathrm{~h}$ during a rain event in October 2019 closely corresponded to the hydrograph profiles at the sampling sites, with the HMMM concentrations peaking $>6 \mathrm{~h}$ after the peak in water levels. This work contributes to the literature showing that HMMM is a ubiquitous contaminant of urban watersheds and that runoff from roads is a vector for the transport of this compound into urban surface waters.
\end{abstract}

Hexamethoxymethyl melamine (HMMM) is a crosslinking agent that is widely used in the production of coatings and plastics, as well as in the manufacturing of tires. Due to its wide-spread use, HMMM was included as a compound of interest in the "High Production Volume (HPV) Challenge Program" established by the U.S. Environmental Protection Agency. There have been sporadic reports of HMMM being detected in surface waters around the globe. Bobeldijk et al. (2002) were the first to report detecting HMMM in surface waters in a study conducted in the Netherlands. This compound was again detected in surface waters in the Netherlands following an alert from a Daphnia biomonitoring system upstream from a drinking water treatment plant (De Hoogh et al. 2006). Dsikowitzky and Schwarzbauer (2015) monitored HMMM concentrations in rivers in Germany over the period between 2000 and 2013 and reported concentrations ranging from 0.01 to $0.88 \mu \mathrm{g} / \mathrm{L}$. Very recently, Rauert et al. (2020) reported that HMMM was detected in passive

Cassandra Johannessen

cjohannessen@trentu.ca

1 Water Quality Center, Trent University, Peterborough, ON, Canada

2 Ontario Ministry of Environment, Conservation and Parks, Toronto, ON, Canada samplers deployed in waterways in Australia. The presence of HMMM in the aquatic environment has been linked to industrial discharges of wastewater from car manufacturing plants (Dsikowitzky and Schwarzbauer 2015; Krauss et al. 2019) and from textile plants (Labunska et al. 2012). Municipal wastewater treatment plants also have been identified as point sources of HMMM (Alhelou et al. 2019).

HMMM may enter surface waters from urban runoff. Eberhard et al. (2015) detected elevated concentrations of HMMM in stormwater retention basins, with a maximum concentration of $2.29 \mu \mathrm{g} / \mathrm{L}$. The presence of HMMM in stormwater indicates that this compound may enter the aquatic environment through runoff from impermeable road surfaces. Seitz and Winzenbacher (2017) detected HMMM at a concentration of $0.66 \mu \mathrm{g} / \mathrm{L}$ in runoff from a highway in Germany. Furthermore, HMMM readily leaches from tire material, confirming that HMMM is a chemical constituent of tire wear particles (Peter et al. 2018). HMMM has been used as an indicator for the presence of leachates from tire wear particles in road runoff (Seitz and Winzenbacher 2017; Peter et al. 2019; Warner et al. 2019; Hou et al. 2019; Tian et al. 2020).

Mass mortalities of adult Coho salmon (Oncorhynchus kisutch) linked to storm events have been observed in spawning streams near urban centers in the Pacific 
northwest region of the United States (Chow et al. 2019), but it was not clear what pollutants of stormwater origin were responsible for inducing these mortalities. Peter et al. (2018) used mortality-linked studies of the constituents in road runoff and in urban receiving waters near Seattle, Washington, and found a range of candidate compounds that could be causing these mortalities, as well as a variety of surrogate compounds that could be considered for risk assessment. In this study, HMMM was detected as either the largest or second largest peak area feature in every mortality signature. Several precursor compounds and transformation products of HMMM also were tentatively identified in the runoff and in the urban streams (Peter et al. 2018). Alhelou et al. (2019) investigated the transformation of HMMM in activated sludge and identified 21 transformation products. Recently, variations in the concentrations of HMMM and other contaminants of urban origin in an urban stream in Seattle were linked to the hydrological cycles during rain events (Peter et al. 2020).

The present study builds upon these earlier investigations to establish a link between the presence of HMMM at elevated concentrations in urban watersheds and runoff from road surfaces. Two urban rivers impacted by major highways in the Greater Toronto Area, the most populous city in Canada, were monitored over several large rain events and a period of rapid snow melt. Total wet event composite samples and separate through-event samples were collected from the Don River and Highland Creek. The Don River watershed contains the Don Valley Parkway and stretches of the 400 series (King's) highways 401 , 404, and 407, and several branches of Highland Creek are intersected by Highway 401. Surface water concentrations were determined via analysis by ultra-high-pressure liquid chromatography with high resolution mass spectrometry (UHPLC-HRMS).

\section{Methods and Materials}

\section{Chemicals}

HMMM was purchased from Alfa Chemistry (New York, $\mathrm{NY}$ ), and atrazine- $\mathrm{d}_{5}$ was purchased from Sigma-Aldrich (Oakville, ON, Canada). The salts used for the preparation of a moderately hard water matrix also were procured from Sigma-Aldrich. HPLC grade solvents and formic acid were purchased from Fisher Scientific (Ottawa, ON, Canada).

\section{Sample Collection}

Surface water samples were collected from the Don

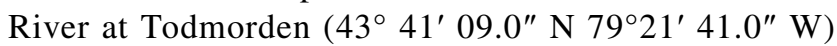

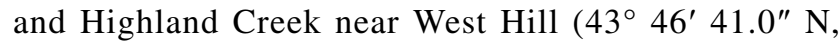
$79^{\circ} 11^{\prime} 29.0^{\prime \prime} \mathrm{W}$ ) in the Greater Toronto Area (GTA) in the province of Ontario, Canada (Fig. 1). The Don River discharges into the Toronto Harbour embayment of Lake Ontario, while Highland Creek discharges directly into the coastal zone of Lake Ontario in the eastern part of the GTA. The characteristics of the sampling sites, including the proximity to major highways, basin drainage area, average discharge, estimated population in the basin and land use data are included in the Supplemental Information (Table S1). The Don River sampling location is located downstream of the North 7 Toronto Wastewater Treatment Plant (WWTP).

Sampling of surface water from these locations was done in collaboration with research personnel from the Ontario Ministry of the Environment Conservation and Parks (MECP) that were simultaneously conducting a study on the transport of nutrients into urban rivers in the GTA. Collections of surface waters were achieved using ISCO Avalanche refrigerated automated samplers (Avensys Systems, Toronto, Ontario, Canada) that were triggered when levels began to rise during major $(>10 \mathrm{~mm})$ rain events on multiple occasions through the fall of 2019 to the early spring of 2020 .

Samples were collected hourly in $300-\mathrm{mL}$ aliquots over a 42-h period, with three aliquots included in each bottle, representing a 3-h composite sample. Flow weighted samples were then prepared by removing subsamples from each bottle in volumes weighted according to the water level in the river. These flow-weighted sample were collected from each location to represent the average contaminant concentration over the $42 \mathrm{~h}$ after the start of the hydrological event. In the fall of 2019, sampling occurred on October 16-17 and October 22-23 for both locations. Sampling also occurred on January 11-12 and January 24-26 in the winter of 2020 and March 29-30 in early spring of that year. However, no samples were collected from the Don River location on January 24-26 and the Highland Creek location on March 29-30 due to technical problems with the autosamplers. In addition, samples were collected from both locations during a period of snow melt on March 2-4, 2020. During the October 16-17 sampling date, temporal profile samples also were collected from each location to monitor the concentration of HMMM over the course of the major rain event. Temporal (hourly) samples were collected every hour for $42 \mathrm{~h}$ and then pooled in 3-h increments to make a total of 14 temporal samples per site.

All samples were collected at the site in polyethylene bottles. Aliquots were then subsampled to polyethylene terephthalate (PET) bottles. Samples were retrieved from sites within $24 \mathrm{~h}$ of the last collection, subsampled at the MECP lab and stored frozen $\left(-18^{\circ} \mathrm{C}\right)$, then transported 


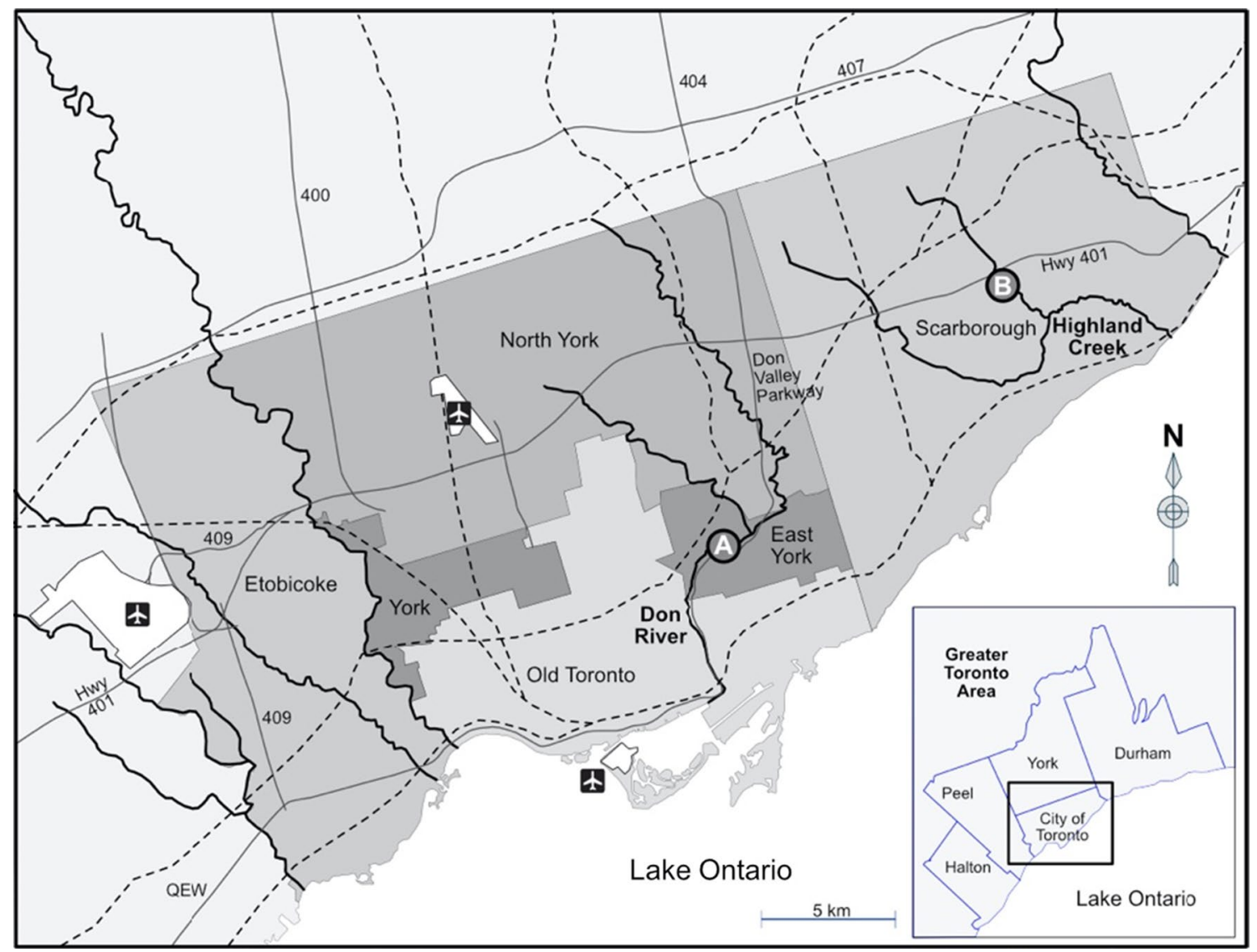

Fig. 1 Locations of the two surface water sampling sites $(\mathrm{A}=\mathrm{D}$ Don River, $\mathrm{B}=$ Highland Creek) in the Greater Toronto Area (GTA) in Ontario, Canada. The map outlines geographical features, such as

to Trent University in coolers where they were kept frozen until subsequent sample processing.

Precipitation data for Toronto were collected from an online data base entitled "Toronto Historical Total Precipitation" available at toronto.weatherstats.ca/metrics/precipitation.html. Real-time hydrometric data were accessed online from a data base maintained by Environment and Climate Change Canada (i.e., wateroffice.ec.gc.ca) for Station $02 \mathrm{HC} 024$ on the Don River and Station $02 \mathrm{HC} 013$ on Highland Creek.

\section{Extraction}

After thawing, each sample was vacuum filtered through 1.5$\mu \mathrm{m}$ glass fiber filters to remove any suspended particulates. The samples were then adjusted to a $\mathrm{pH}$ of $7.0 \mathrm{using} 3.0 \mathrm{M}$ $\mathrm{H}_{2} \mathrm{SO}_{4}$ or $1.0 \mathrm{M} \mathrm{NaOH}$. Care was taken to ensure that the sample $\mathrm{pH}$ remained above 6 to avoid spontaneous polymerization of HMMM (Eberhard et al. 2015). The samples were mixed by repeated inversion, and $50-\mathrm{mL}$ aliquots of each sample were taken for further processing in triplicate. Because there are no stable isotope labelled surrogates of highways (grey lines), rivers (bold lines), railways (dashed lines), and the various municipal districts in the GTA (shades of grey)

HMMM available from commercial suppliers, atrazine- $\mathrm{d}_{5}$ was used as an internal standard (IS). Both atrazine and HMMM are triazine compounds, and they have similar log Kow values and chromatographic retention times. Atrazine$\mathrm{d}_{5}$ was spiked into each 50 -mL sample from a stock solution at a concentration of $500 \mu \mathrm{g} / \mathrm{L}$ using volumes of either $100 \mu \mathrm{L}$ for composite samples or $50 \mu \mathrm{L}$ for temporal profile samples.

Analytes were extracted using Oasis hydrophilic-lipophilic balance (HLB) SPE cartridges (6 cc, $500 \mathrm{mg}$ ) purchased from Waters (Milford, MA), using a method based on the SPE procedure described by Miao and Metcalfe (2003). The cartridges were manually preconditioned with $6 \mathrm{~mL}$ of acetone, $6 \mathrm{~mL}$ of methanol, and $6 \mathrm{~mL}$ of MilliQ water (adjusted to $\mathrm{pH}=7.0$ with $3.0 \mathrm{M} \mathrm{H}_{2} \mathrm{SO}_{4}$ ), sequentially. Using Teflon tubing, each 50-mL water sample was passed through the cartridge at a rate of $2.5 \mathrm{~mL} / \mathrm{min}$. Each empty sample jar was washed with $10 \mathrm{~mL}$ of MilliQ water, and this rinse was allowed to pass through the cartridge. Once the meniscus of the rinse reached the SPE sorbent, the vacuum was turned off. An additional 2-mL rinse of MilliQ water was added directly to the cartridge and allowed to flow through. The 
cartridges were then aspirated under vacuum for $5 \mathrm{~min}$. The samples were eluted with $9 \mathrm{~mL}$ of HPLC grade methanol in $3-\times 3-\mathrm{mL}$ aliquots at a rate of $1 \mathrm{~mL} / \mathrm{min}$. Before each aliquot was allowed to elute, the solvent was left in the cartridge to equilibrate for $6 \mathrm{~min}$. After the last volume of methanol passed through, the cartridges were once again aspirated under vacuum for $5 \mathrm{~min}$. The eluates were collected in glass centrifuge tubes and immediately concentrated to a final volume of $1 \mathrm{~mL}$. Samples were then transferred to amber sample vials and stored in the fridge until analysis by LC-HRMS.

\section{Analysis}

The compounds in samples were separated chromatographically with a Thermo (Waltham, MA) Ultimate 3000 UHPLC system with a WPS-3000 autosampler using a Kinetex $2.6 \mu \mathrm{m}$ C18 column $(50 \times 4.6 \mathrm{~mm})$ purchased from Phenomenex (Torrance, CA). The sample injection volume was $25 \mu \mathrm{L}$. The column operated at room temperature with a flow rate of $500 \mu \mathrm{L} / \mathrm{min}$ with a binary gradient, based on the method described by Alhelou et al. (2019). Mobile phase A consisted of MilliQ water $(\mathrm{pH}=7)$ with $0.1 \%$ formic acid and mobile phase $B$ consisted of methanol with $0.1 \%$ formic acid. A ramp gradient totaling 17 min was employed and consisted of increasing mobile phase B from 2 to $99 \%$ in 12.25 min. Mobile phase B was then held at this proportion for $2.75 \mathrm{~min}$ and then brought back down to $2 \%$ in $0.1 \mathrm{~min}$. The system was left to equilibrate for $1 \mathrm{~min}$ before the next injection.

Samples were analyzed by HRMS using a Thermo Q Exactive Orbitrap (Waltham, MA) with a heated electrospray ionization source (HESI-II) operated in positive mode at a resolution of 140,000 to reduce possible interferences. The sheath gas flow rate was 50 AU (arbitrary units), auxiliary gas flow rate was $15 \mathrm{AU}$, and the sweep gas flow rate was $0 \mathrm{AU}$. The spray voltage was operated at $3.5 \mathrm{kV}$ and the S-lens RF level was $50 \mathrm{AU}$. The capillary and auxiliary gas heater temperatures were $320{ }^{\circ} \mathrm{C}$ and $300{ }^{\circ} \mathrm{C}$, respectively. Data acquisition was achieved using targeted selected ion monitoring (t-SIM) at $\mathrm{m} / z 391.22996$ and 221.13243 for protonated HMMM and atrazine- $\mathrm{d}_{5}$, respectively. Both analytes were fragmented at a normalized collision energy of $20 \%$.

A 10-point calibration curve consisting of HMMM ranging in concentrations from 1.25 to $100 \mu \mathrm{g} / \mathrm{L}$ plus the IS was analyzed directly before the samples. Samples were quantified by peak area based on Genesis automated integration using Xcalibur $^{\mathrm{TM}}$ software (version 3.0.63) and were corrected for method recovery based on the concentration of the IS. Blanks consisting of the reagent (methanol) were run at the beginning, middle, and end of the sample sequence to look for carryover, interferences, and background contamination. Standard solutions containing the analytes of interest (QC samples) were run at the beginning, middle, and end of the sample sequence to assess instrumental sensitivity drift.

\section{Quality Assurance}

Field blanks consisting of HPLC-grade deionized water in polyethylene ISCO bottles were transported, processed, transferred to PET bottles, and stored in the same manner as river water samples. In addition, deionized MilliQ water was extracted as laboratory blanks with every batch of 6-7 river water samples. Recovery experiments were performed to assess method accuracy and bias. To do so, $250 \mu \mathrm{g} / \mathrm{L}$ of HMMM was spiked into Otonabee River (Peterborough, ON) water and processed in triplicate with a five-point calculation curve $\left(R^{2}=0.996\right)$ at concentrations ranging from 100 to $300 \mu \mathrm{g} / \mathrm{L}$. Blanks of Otonabee River water were also processed without an HMMM spike to determine if there was background contamination in this rural river system. The spike and recovery experiments showed an average percent recovery of $106 \%$, which indicated that there was no significant signal enhancement or suppression. In addition, no background contamination of HMMM was detected in the Otonabee River samples.

The limit of detection (LOD) and limit of quantification (LOQ) for HMMM were determined by spiking synthetic surface water with a calibration standard at a low concentration, followed by the same sample extraction and analysis procedures used for surface water samples. "US EPA Medium Hard Water," which contains no dissolved organics and is at a standardized.

$\mathrm{pH}$ of 7.5 , hardness of $80 \mathrm{mg} / \mathrm{L}$, and alkalinity of $60 \mathrm{mg} / \mathrm{L}$. This matrix was selected for LOD/LOQ determination as the water quality parameters are consistent and similar to the surface water samples. In brief, the synthetic water was prepared by dissolving in $1 \mathrm{~L}$ of MilliQ water $(18 \Omega), 96 \mathrm{mg}$ of $\mathrm{NaHCO}_{3}, 60 \mathrm{mg}$ of $\mathrm{CasO}_{4} \bullet \mathrm{H}_{2} \mathrm{O}, 60 \mathrm{mg}$ of $\mathrm{MgSO}_{4}$, and $4.0 \mathrm{mg} \mathrm{KCl}$. Following equilibration overnight, the water was divided into eight aliquots of $50 \mathrm{~mL}$ each, which were then spiked with $250 \mu \mathrm{L}$ of a $10 \mathrm{ng} / \mathrm{mL}$ stock solution of HMMM and $30 \mu \mathrm{L}$ of a $500 \mathrm{ng} / \mathrm{mL}$ stock solution of the IS. These aliquots underwent sample processing as described above for each river water sample. The standard deviation (SD) around the analytical results of the eight replicates were calculated. The LOD and LOQ were defined as the SD multiplied by 3 and 10 , respectively.

\section{Results and Discussion}

HMMM was not detected in any of the reagent blanks, laboratory blanks, or field blanks, indicating that there was no contamination during sample collection and any step of the analytical method. As a result, no blank correction 
was required. The concentrations of HMMM in standard dilution quality control samples were always within $10 \%$ of the expected value, indicating that there was not significant instrumental sensitivity drift during analysis. All samples were quantified with a 10-point calibration curve $\left(\mathrm{R}^{2} \geq 0.996\right)$ that had a linear detection range that spanned almost two orders of magnitude. HMMM had a retention time of $12.8 \mathrm{~min}$, and the IS had a retention time of $13.2 \mathrm{~min}$. There was no significant alteration in the retention times for either analyte between runs on the same day, as well as between days. The LOD and LOQ values for HMMM were $0.02 \mu \mathrm{g} / \mathrm{L}$ and $0.06 \mu \mathrm{g} / \mathrm{L}$, respectively.

HMMM was detected above LOQs in all samples of river water from both locations in Toronto. The average recovery of the IS for the field samples was $81 \%$, with a standard deviation of $9.8 \%$. The concentration of HMMM in each of the field samples are provided in the Supplemental Information (Table S2 and S3), along with the associated standard deviations (SD) and percent relative standard (\% RSD) deviations, where applicable. The mean concentrations of HMMM in the composite samples from the Don River and Highland Creek are summarized in Fig. 2. These data represent the flow-weighted average concentration of this contaminant in the river water from over a 42-h period directly following the start of the rain event, or in the case of the samples collected from March $2-4$, over the course of rapid snow melt followed by moderate precipitation $(9.0 \mathrm{~mm})$. The $\%$ RSD for these samples analyzed in triplicate was always $<10 \%$.

The concentration of HMMM in the flow-weighted event composite samples from the Don River and Highland Creek increased almost proportionally for the two locations between the October 16-17 and the October 22-23 sampling dates. This is inversely proportional to the relative amounts of rainfall that occurred on these two dates, as the higher concentration of HMMM was detected on the date with a lower amount of recorded precipitation. For example, there was $18.2 \mathrm{~mm}$ of rain on October 16 and only $10.6 \mathrm{~mm}$ of rain on October 22. There apparent trend also holds true for the total precipitation and concentrations in surface waters collected over the winter sampling dates, as the greatest rainfall of any of the sampling days occurred on January 11, the day in which the lowest concentrations of HMMM were observed for the Highland Creek site and reduced concentrations were observed for the Don River location. This suggests that there may be a dilution effect occurring, wherein reduced concentrations of HMMM are observed when there are higher flows due to greater amounts of precipitation. However, when the total mass loadings of HMMM (g/ event) at the two locations were calculated and compared to the intensity of the storm events, as indicated by the total amount of precipitation $(\mathrm{mm})$, there were no apparent relationships observed (Table S4; Fig. S1), indicating that the flux in the concentrations of HMMM were not simply due to a dilution effect. However, the concentration trend may be attributed, at least in part, to the increased dry period (days of no precipitation) that occurred before sampling. For example, there was a 5-day dry period before sampling on October 22 compared with a 3-day dry period before sampling on October 17. Extended dry periods between rain events allows for a build-up of tire wear materials on the highways, possibly resulting in a higher concentration of this contaminant in road runoff during a rain event (Opher and Friedler 2010). To explore this concept, a plot comparing the average HMMM concentration and the length of the antecedent dry period is presented in Supplemental Information
Fig. 2 Mean $(n=3)$ concentrations $(\mu \mathrm{g} / \mathrm{L})$ of HMMM in surface waters from the Don River (dark grey bars) and Highland Creek (light grey bars) from flow-weighted composite samples taken over the course of hydrological events in the Greater Toronto Area (GTA). The error bars represent standard deviations about the mean. Precipitation amounts $(\mathrm{mm})$ over the sampling dates are presented in as light grey dots

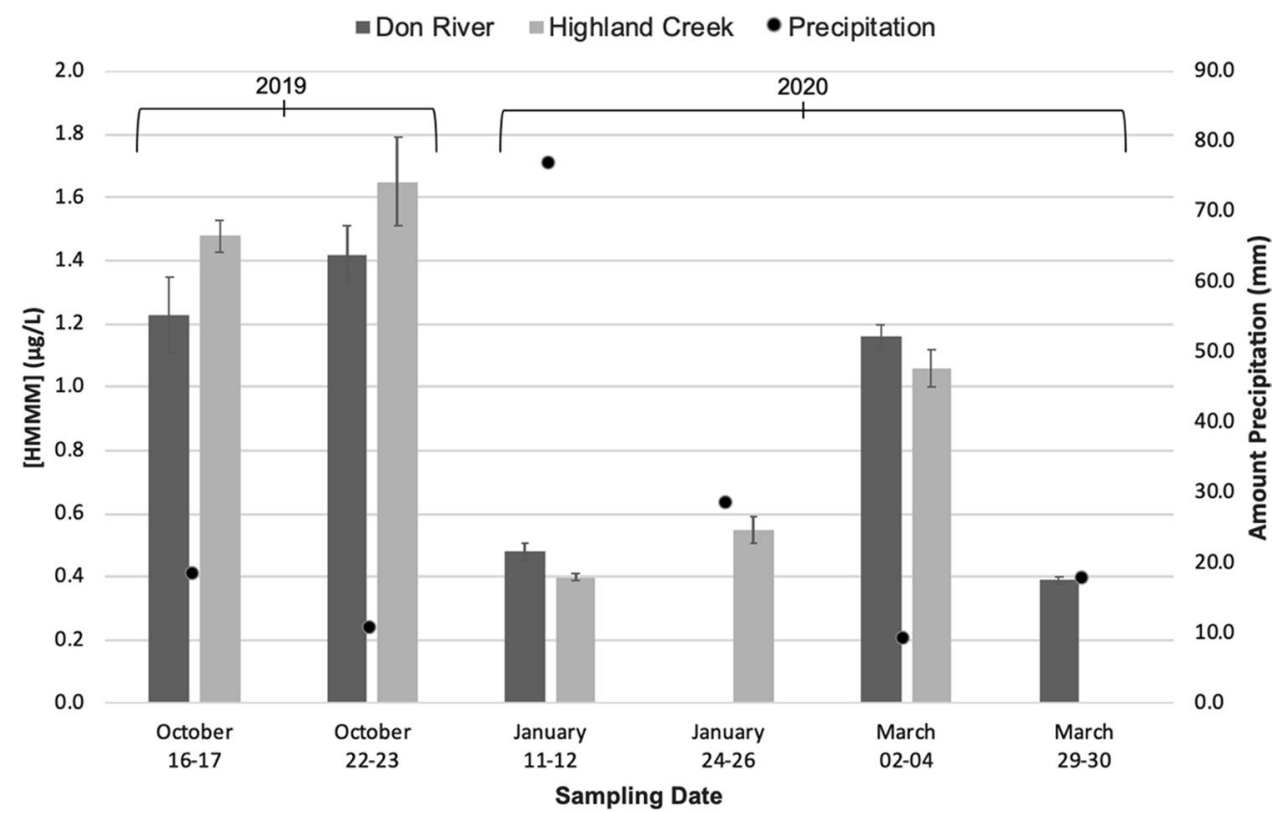


(Fig. S2). This plot shows that there is a positive, linear relationship between the concentration and the length of the antecedent dry period. The data on the recorded precipitation on the sampling dates, as well as the length of the dry period preceding each sampling event are summarized in Supplemental Information (Table S5).

At both locations, elevated concentrations ( $>1 \mu \mathrm{g} / \mathrm{L}$ ) of HMMM were detected during rain events in October of 2019 compared with rain events in January and late March 2020 $(<0.55 \mu \mathrm{g} / \mathrm{L})$. According to leaching experiments performed by Peter et al. (2020), these HMMM concentrations correspond to tire wear particle concentrations of $\sim 65 \mathrm{mg} / \mathrm{L}$ and $\sim 15 \mathrm{mg} / \mathrm{L}$, respectively. These estimated tire wear particle concentrations may explain the observed concentrations of HMMM, but these are only crude estimates and may underrepresent the actual equivalent amounts of tire wear particles present in the rivers.

The variation in HMMM between fall and winter sampling indicates that the contamination of HMMM in urban surface waters as a result of road runoff may be subject to seasonal variations. In the future, leaching experiments should be done on summer and winter tires to determine whether there are significant differences in the quantities of HMMM released from these two tire types, which may explain, in part, the apparent seasonal variations. However, it also is possible that the cold temperatures during the winter reduce the mobility of HMMM, making it less likely to leach into water and be detected by these sampling methods. Seasonal trends reflecting lower concentrations of HMMM in receiving waters in winter months were recently reported by Peter et al. (2020) and Rauert et al. (2020). These other reported trends are consistent with our suggestion that HMMM is subject to seasonal variation.

Notably, relatively high concentrations of HMMM were found in both rivers during the snowmelt event in early March 2020. This indicates that HMMM may be sequestered in the snow, accounting for lower mobility during the winter.
Also of interest is the reduced concentration of HMMM observed in samples of surface water from the Don River collected during March 29-30, which was triggered by a rain event with $17.6 \mathrm{~mm}$ of precipitation. This sampling occurred during the COVID-19 pandemic when traffic volumes were reduced in the GTA due to social isolation directives and closed businesses. Nevertheless, it is difficult to speculate if the pandemic influenced the concentration of HMMM detected as only a single event was monitored.

Figure 3 presents the concentrations of HMMM found in the temporal profile samples collected from the Don River and Highland Creek on October 16-17. Here, sampling was triggered $2 \mathrm{~h}$ after the start of the rain event. These figures also show the discharge in $\mathrm{m}^{3} / \mathrm{s}$ measured at the start of each 3-h interval in the rivers plotted alongside the HMMM concentrations. The hydrograph and the concentration profile for HMMM for each site have noticeably similar shapes that become more apparent by viewing the continuous hydrograph profiles, which are included in Supplemental Information (Fig. S3). The concentrations of HMMM in the receiving waters increased dramatically in response to the start of the rain event, despite the dilution caused by the influx of water, confirming runoff as a significant vector for contaminant transport. There is a notable time lag $(>6 \mathrm{~h})$ between the peak discharge and the peak concentration for both locations. This can likely be attributed to the fact that the runoff from adjacent roadways takes some time to reach the receiving waters. Thus, the flow rate increased almost immediately, but because the chemicals in the road runoff must travel a distance overland to reach the river, the temporal profiles for the concentration of HMMM lagged behind the rate of river flow. There also is a noticeable lag time between peak concentration and the commencement of the rain event, and this lag time differs slightly between the two locations. The highest concentration of HMMM in Don River of $1.74 \mu \mathrm{g} / \mathrm{L}$ was detected $14-17 \mathrm{~h}$ after the start of the
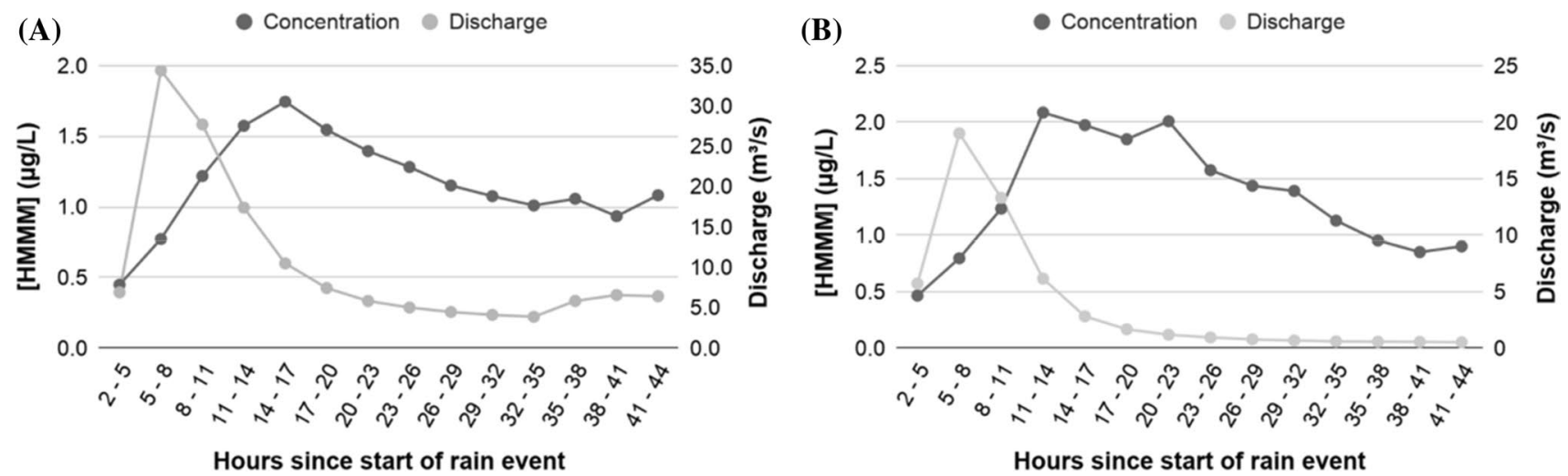

Fig. 3 Concentrations in $\mu \mathrm{g} / \mathrm{L}$ (dark grey) of HMMM in the Don River (a) and Highland Creek (b) with the discharge in $\mathrm{m}^{3} / \mathrm{s}$ (light grey) tracked over the course of a rain event 
rain event. Similarly, the highest concentration of HMMM in Highland Creek of $2.08 \mu \mathrm{g} / \mathrm{L}$ occurred $11-14 \mathrm{~h}$ after the start of the rain event. This lag time likely stems from the time required for HMMM present in the road runoff to reach the receiving waters, which is dependent on the terrain, bulk density, and porosity of the soil and distance from the highway at the two sampling locations. Note that the distance from the road to the sampling point in the Don River was estimated as $30 \mathrm{~m}$, but the distance in meters from the road to Highland Creek was estimated as zero, because the major Highway 401 passes over the creek as a concrete bridge. These estimated distances do not consider the distances to stormwater outfalls, drains from catch basins, or surface drains from bridges.

To further define the flush dynamics of HMMM for these locations, curves describing the dimensionless normalized cumulative load versus normalized cumulative volume (i.e., $\mathrm{M}-\mathrm{V}$ curves) were generated from the temporally resolved data (Fig. 4). The normalized cumulative runoff volume was calculated using discharge data for the receiving water site, as described by Peter et al. (2020). These plots indicate that HMMM underwent a "first flush" process at both locations, with $>60 \%$ of pollutant mass transported in the initial $20-30 \%$ of the runoff volume. After this initial first flush, the $\mathrm{M}-\mathrm{V}$ curve tends towards a 1:1 relationship defining the mass load to runoff curve. This indicates that the transport of HMMM through runoff remains strong even during latter parts of the storm event, supporting the hypothesis presented by Peter et al. (2020) that the flux of HMMM is transportlimited rather than mass-limited.

HMMM at similar $\mu \mathrm{g} / \mathrm{L}$ concentrations was previously detected in river water in Germany (Eberhard et al. 2015; Dsikowitzky and Schwarzbauer 2015; Alhelou et al. 2019). However, the concentrations in the present study are significantly higher than those reported by Peter et al. (2018) for

\section{(A)}

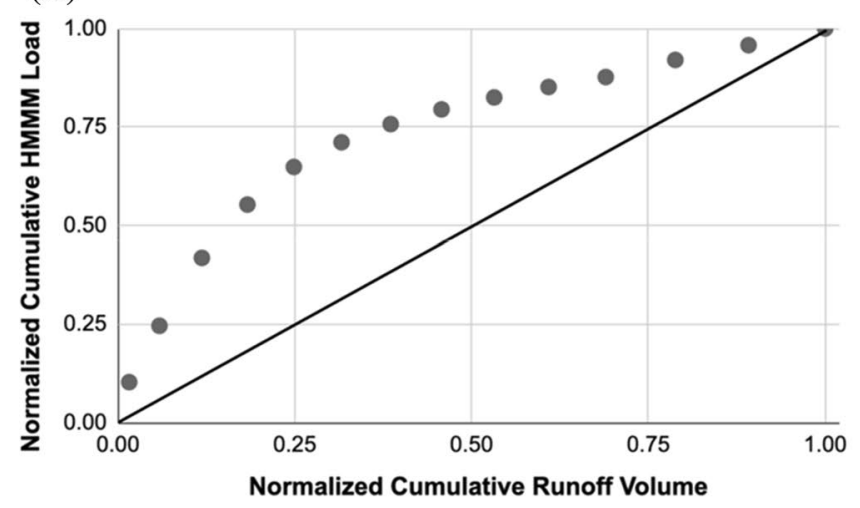

Fig. 4 Normalized cumulative load versus normalized cumulative volume curves (i.e., M-V curves) for HMMM during the October 16-17, 2020 rain event for the Don River (a) and Highland Creek (b). creeks in the area of the city of Seattle in Washington State, USA in which $8-13 \mathrm{ng} / \mathrm{L}$ of HMMM were detected during baseflow conditions and 30 to $\sim 200 \mathrm{ng} / \mathrm{L}$ were detected during storm events in the fall of 2016 and 2017. The concentrations of HMMM detected in the Don River and Highland Creek are also elevated compared to concentrations of $0.5-130 \mathrm{ng} / \mathrm{L}$ reported by Hou et al. (2019) from grab samples of surface water collected during a rain event in June 2018 from various creeks in the Puget Sound region of Washington State, USA. Finally, the HMMM concentrations in the present study also are higher than the concentrations of HMMM estimated from passive samplers deployed in surface waters in Australia (Rauert et al. 2020).

Notably, there has been one other recent study that investigated the pollution characteristics of HMMM in receiving waters in response to rain events. Peter et al. (2020) observed that the concentration of HMMM and other contaminants in urban runoff increased dramatically during a rain event, although the temporal samples were not resolved enough to determine where the concentration maximum for HMMM occurred relative to the hydrograph peak. Nevertheless, this previous study demonstrated that runoff mobilizes this contaminant. As mentioned previously, the data from the study by Peter et al. (2020) was consistent with the suggestion that there was a seasonal variation in HMMM contamination observed in the present study, as these researchers observed HMMM concentrations reaching a maximum of $1.48 \mu \mathrm{g} / \mathrm{L}$ in October and decreasing to $0.35 \mu \mathrm{g} / \mathrm{L}$ in November. These are very similar to the mean concentrations of HMMM detected in the present study in composite samples collected during October 2019 (i.e., $1.45 \mu \mathrm{g} / \mathrm{L}$ across sites and dates) and

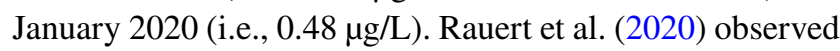
a similar seasonal trend of higher estimated concentrations of HMMM in Australian waterways during the Austral summer compared with the levels in winter.
(B)

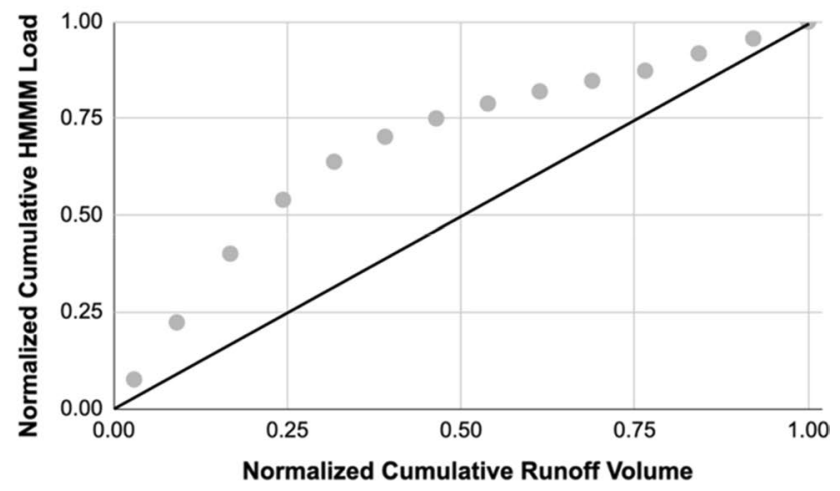

Diagonal lines represent a uniform (1:1) pollutant wash off rate during storm event 
What remains to be determined is whether these $\mu \mathrm{g} / \mathrm{L}$ concentrations of HMMM and potentially its transformation products are a threat to aquatic life. As a result, additional research is needed to assess the toxicity and effects of HMMM and other tire wear compounds transported into surface waters from road runoff. McIntyre et al. (2018) showed that Coho salmon (Oncorhynchus kisutch) are particularly susceptible to the toxic effects of the chemicals that are transported into urban streams in the northwestern United States. In the Lake Ontario basin, a range of native and nonnative salmonids, including introduced Coho salmon are present in the coastal areas and tributaries (Morrison 2019). It is possible that HMMM and other contaminants in urban streams in the Lake Ontario basin are stressors for these and other fish species.

\section{Conclusions}

This study contributes to the growing literature showing that HMMM is a ubiquitous contaminant in urban watersheds and runoff from roads in high traffic areas can be a major nonpoint source of this compound. The concentrations of HMMM in surface waters adjacent to two major highways in the GTA were elevated to low $\mu \mathrm{g} / \mathrm{L}$ concentrations in response to rain events and also during a period of rapid snow melt. Future studies should focus on determining whether this compound and its transformation products are toxic to aquatic organisms in receiving waters. Mitigation of these effects may be possible by developing "bioinfiltration" solutions to sequester the toxic compounds before they reach surface waters (Spromberg et al. 2016). On a broader issue, more work is needed to evaluate whether the mix of organic and inorganic contaminants, as well as major ions and nutrients present in road runoff are a significant threat to the health of aquatic ecosystems, and a source of contamination of drinking water.

Supplementary Information The online version of this article (https:// doi.org/10.1007/s00244-021-00815-5) contains supplementary material, which is available to authorized users.

Acknowledgements Many thanks to John Thibeau from the Ontario Ministry of Environment Conservation and Parks for collecting and pre-processing the surface water samples. Thank you to Lauren Barth from the Ontario Ministry of Environment Conservation and Parks for aid with the tasks surrounding the mass loading calculations. In addition, thank you for Eric Wootton for his numerous readings of the manuscript for clarity.

Funding This work was funded by a Discovery Grant to Chris Metcalfe from the Natural Sciences and Engineering Research Council (NSERC) of Canada.
Data Availability Statement Raw data are available upon request to Chris Metcalfe (cmetcalfe@ trentu.ca).

\section{Compliance with Ethical Standards}

Conflict of interest The authors declare no conflicts of interest or competing interests.

\section{References}

Alhelou R, Seiwert B, Reemtsma T (2019) Hexamethoxymethylmelamine: a precursor of persistent and mobile contaminants in municipal wastewater and the water cycle. Water Res 165:114973. https://doi.org/10.1016/j.watres.2019.114973

Bobeldijk I, Stoks PGM, Vissers JPC, Emke E, Van Leerdam JA, Muilwijk B, Berbee R, Noij THM (2002) Surface and wastewater quality monitoring: combination of liquid chromatography with (geno)toxicity detection, diode array detection and tandem mass spectrometry for identification of pollutants. J Chromatogr A 970:167-181. https://doi.org/10.1016/S0021-9673(02)00398-9

Chow MI, Lundin JI, Mitchell CJ, Davis JW, Young G, Scholz NL, McIntyre JK (2019) An urban stormwater runoff mortality syndrome in juvenile coho salmon. Aquat Toxicol. https://doi. org/10.1016/j.aquatox.2019.105231

De Hoogh CJ, Wagenvoort AJ, Jonker F, Van Leerdam JA, Hogenboom AC (2006) HPLC-DAD and Q-TOF MS techniques identify cause of Daphnia biomonitor alarms in the River Meuse. Environ Sci Technol 40:2678-2685. https://doi.org/10.1021/es052035a

Dsikowitzky L, Schwarzbauer J (2015) Hexa(methoxymethyl)melamine: an emerging contaminant in german rivers. Water Environ Res 87:461-469. https://doi.org/10.2175/106143014x1406052364 0919

Eberhard S, Foht S, Potouridis T, Puttmann W (2015) High concentrations of hexamethoxymethylmelamine (HMMM) in selected surface waters in southern Hesse. Gesellschaft Dtsch Chem Umweltchemie und Ökotoxikologie

Hou F, Tian Z, Peter KT, Wu C, Gipe AD, Zhao H, Alegria EA, Liu F, Kolodziej EP (2019) Quantification of organic contaminants in urban stormwater by isotope dilution and liquid chromatographytandem mass spectrometry. Anal Bioanal Chem 411:7791-7806. https://doi.org/10.1007/s00216-019-02177-3

Krauss M, Hug C, Bloch R, Schulze T, Brack W (2019) Prioritising site-specific micropollutants in surface water from LC-HRMS non-target screening data using a rarity score. Environ Sci Eur 31:45. https://doi.org/10.1186/s12302-019-0231-z

Labunska I, Brigden K, Santillo D, Johnston P (2012) Organic chemical and heavy metal contaminants in wastewater discharged from three textile manufacturing and washing facilities in Mexico. Exeter

McIntyre JK, Lundin JI, Cameron JR, Chow MI, Davis JW, Incardona JP, Scholz NL (2018) Interspecies variation in the susceptibility of adult Pacific salmon to toxic urban stormwater runoff. Environ Pollut 238:196-203. https://doi.org/10.1016/j.envpol.2018.03.012

Miao XS, Metcalfe CD (2003) Determination of carbamazepine and its metabolites in aqueous samples using liquid chromatography: electrospray tandem mass spectrometry. Anal Chem 75:37313738. https://doi.org/10.1021/ac030082k

Morrison BP (2019) Chronology of Lake Ontario ecosystem and fisheries. Aquat Ecosyst Heal Manag 22:294-304. https://doi. org/10.1080/14634988.2019.1669377 
Opher T, Friedler E (2010) Factors affecting highway runoff quality. Urban Water J 7:155-172. https://doi.org/10.1080/1573062100 3782339

Peter KT, Hou F, Tian Z, Wu C, Goehring M, Liu F, Kolodziej EP (2020) More than a first flush: Urban creek storm hydrographs demonstrate broad contaminant pollutographs. Environ Sci Technol 54:6152-6165. https://doi.org/10.1021/ACS.EST.0C00872

Peter KT, Tian Z, Wu C, Lin P, White S, Du B, McIntyre JK, Scholz NL, Kolodziej EP (2018) Using high-resolution mass spectrometry to identify organic contaminants linked to urban stormwater mortality syndrome in Coho salmon. Environ Sci Technol 52:10317-10327. https://doi.org/10.1021/acs.est.8b03287

Peter KT, Wu C, Tian Z, Kolodziej EP (2019) Application of nontarget high resolution mass spectrometry data to quantitative source apportionment. Environ Sci Technol 53:12257-12268. https://doi. org/10.1021/acs.est.9b04481

Rauert C, Kaserzon SL, Veal C, Yeh RY, Mueller JF, Thomas KV (2020) The first environmental assessment of hexa(methoxymethyl)melamine and co-occurring cyclic amines in Australian waterways. Sci Total Environ 743:140834. https:// doi.org/10.1016/j.scitotenv.2020.140834
Seitz W, Winzenbacher R (2017) A survey on trace organic chemicals in a German water protection area and the proposal of relevant indicators for anthropogenic influences. Environ Monit Assess 189:244. https://doi.org/10.1007/s10661-017-5953-Z

Spromberg JA, Baldwin DH, Damm SE, McIntyre JK, Huff M, Sloan CA, Anulacion BF, Davis JW, Scholz NL (2016) Coho salmon spawner mortality in western US urban watersheds: bioinfiltration prevents lethal storm water impacts. J Appl Ecol 53:398-407. https://doi.org/10.1111/1365-2664.12534

Tian Z, Peter KT, Gipe AD, Zhao H, Hou F, Wark DA, Khangaonkar T, Kolodziej EP, James CA (2020) Suspect and nontarget screening for contaminants of emerging concern in an urban estuary. Environ Sci Technol 54:889-901. https://doi.org/10.1021/acs. est.9b06126

Warner W, Licha T, Nödler K (2019) Qualitative and quantitative use of micropollutants as source and process indicators: a review. Sci Total Environ 686:75-89. https://doi.org/10.1016/j.scito tenv.2019.05.385 